\title{
Experience with surgical options for managing atonic post-partum haemorrhage
}

\author{
Rachana Saha, Chanda Karki, Saraswati M. Padhye \\ Department of Obstetrics \& Gynaecology \\ Kathmandu Medical College Teaching Hospital, Sinamangal, Nepal
}

\begin{abstract}
Aim: To analyse the measures taken for controlling primary Post-partum haemorrhage (PPH).

Methods: A hospital based descriptive and retrospective study was carried out from $1^{\text {st }}$ January 2005 to $31^{\text {st }}$ December 2006 in the department of Obstetrics \& Gynaecology at KMCTH. All patients of having primary Post-partum haemorrhage were analysed for the treatment they received.

Results: There were 15 cases of primary Post-Partum Haemorrhage (PPH) from a total delivery of 700 in the year 2005. 9 cases were solely of atonic post-partum haemorrhage. 2 cases were genital tract injuries, 1 case of retained placenta, 1 case of vulval haematoma and 2 cases were of combined cervical tear and atonic primary post-partum haemorrhage. Atonic post-partum haemorrhage remained most important cause. The most common treatment was use of oxytocic. Surgical procedure bilateral uterine artery ligation was frequently performed in 6 cases but it was not effective as a single procedure. B-Lynch brace suture was applied in 5 cases and was successful without further intervention. There were 2 maternal deaths from post-partum haemorrhage. In the year 2006 total number of deliveries was 835 and there were total 11 cases of post partum haemorrhage. The trend changed to from atonic PPH to traumatic PPH. There were 8 cases of traumatic PPH and there were 2 cases of placenta accrete. There was one case of atonic PPH. The overall incidence in two years was $1.6 \%$.
\end{abstract}

Conclusion: Among the various surgical methods adopted B-Lynch brace suture was found to be simple, effective and minimally invasive.

Keywords: Atonic post-partum haemorrhage (PPH), surgical management of PPH.

\section{Introduction}

Post-partum haemorrhage remains a serious obstetric problem ${ }^{1,2,3,4}$ and contributes to $25-43 \%$ of all maternal deaths in the developing countries. ${ }^{2,3}$ Five percent of vaginal deliveries may lead to post-partum haemorrhage with a blood loss $>1$ litre. ${ }^{1,3}$ Published data suggest a variety of acceptable methods of treatment such as simple bimanual compression, ecbolics such as oxytocin, syntometrine and prostaglandins which are safe and effective but occasionally proves inadequate. ${ }^{1}$ Surgical methods vary depending on the site of bleeding, the severity of the conditions and cardio- vascular stability of the patient. ${ }^{1}$ Various surgical methods to reduce pelvic pressure have been described from simple surgical ligature of the uterine artery to more complicated uterine, ovarian and internal iliac artery ligation. These procedures need skill which may not be normally possessed by the on duty Registrar. Recently B - Lynch, a suture that envelops and compresses the uterus was described by Christopher B - Lynch (1997) in five cases and was successful in managing massive life threatening post-partum haemorrhage where conventional ecbolics had proved ineffective. Sometimes hysterectomy might be the last resort.

Correspondence

Dr. Rachana Saha, $M D$

Lecturer, Department of Obstetrics \& Gynaecology

Kathmandu Medical College Teaching Hospital, Sinamangal, Nepal

Ph. No. 4481903

Email:pnp@healthnet.org.np 


\section{Objective}

\section{General objective}

- To analyse the measures taken for controlling primary Post-partum haemorrhage at KMCTH.

\section{Specific objective}

- To find out the incidence of Post-partum haemorrhage at Kathmandu Medical College Teaching Hospital (KMCTH)

- To find out causes of PPH

- Measures taken to control Post-partum haemorrhage.

\section{Methods}

A hospital based descriptive, observational and retrospective study was carried out at Kathmandu Medical College Teaching Hospital (KMCTH) from a period of $1^{\text {st }}$ January 2005 to $31^{\text {st }}$ December 2006. The study group included the patients who had primary post-partum haemorrhage. All the information was gathered from the record files and concerned treating consultant. Treatment applied was at concerning treating consultant discretion. Blood loss was clinical visual estimate. Patients were followed from the time of event to time of discharge.

\section{Results}

Between $1^{\text {st }}$ January to $31^{\text {st }}$ December 2005 the total number of deliveries at KMCTH was 700. Lower segment Caesarean section was 206, instrumental deliveries were 31 , and there were 15 cases primary post-partum haemorrhage 5 of each was following Caesarean section. There were 2 maternal deaths. The incidence of primary post-partum haemorrhage in one year was $2.1 \%$.

Table I. Types of PPH

\begin{tabular}{lcc}
\hline & 2005 & 2006 \\
\hline Atonic PPH & 8 & 1 \\
Traumatic PPH & 3 & 8 \\
Combined PPH & 3 & - \\
Placental Tissue & 1 & 2 \\
\hline Total & 15 & 11 \\
\hline
\end{tabular}

Table 2. Atonic PPH and Mode of Delivery

\begin{tabular}{lcc}
\hline & 2005 & 2006 \\
\hline Atonic PPH & 8 & 1 \\
During LSCS & 5 & 1 \\
During vaginal delivery & 3 & - \\
maternal death following & 1 & - \\
vaginal delivery & & \\
\hline
\end{tabular}

Table 3. Traumatic PPH

\begin{tabular}{lcc}
\hline & 2005 & 2006 \\
\hline Cervical tear with vaginal wall tear & 1 & - \\
Perienal heamatoma & 1 & 1 \\
Cervical tear & 1 & 4 \\
Scar rupture & - & 1 \\
Reopening of LSCS & - & 2 \\
\hline Total & 3 & 8 \\
\hline
\end{tabular}

Table 4. Combined causes of PPH

\begin{tabular}{lcc}
\hline & 2005 & 2006 \\
\hline Cervical tear with atonic PPH & 2 & - \\
$\begin{array}{l}\text { Coagulapathy with atonic PPH } \\
\text { (Amniotic fluid embolism) }\end{array}$ & 1 & - \\
\hline Total & 3 & 0 \\
\hline
\end{tabular}

Table 5. Placental tissue causes of PPH

\begin{tabular}{lcc}
\hline & 2005 & 2006 \\
\hline $\begin{array}{l}\text { Retained placenta }- \\
\text { placenta accreta }\end{array}$ & 1 & 2 \\
\hline
\end{tabular}

Table 6. Treatment analysis of atonic PPH

\begin{tabular}{lcc}
\hline & 2005 & 2006 \\
\hline Massage & 8 & 1 \\
Ecbolics & 8 & 1 \\
Bilateral uterine artery ligation & 6 & - \\
Bilateral ovarian artery ligation & 1 & - \\
B-Lynch brace suture & 5 & - \\
Balloon tamponade & 1 & - \\
Hysterectomy & Nil & - \\
Blood transfusion & 8 & - \\
\hline
\end{tabular}


In the year 2006 total number of deliveries was 835 and there were total 11 cases of post partum haemorrhage. The incidence was 1.32 . The trend changed to from atonic PPH to traumatic PPH. There were 8 cases of traumatic $\mathrm{PPH}$ and there were 2 cases of placenta accrete. There was one case of atonic PPH. Overall incidence was $1.6 \%$ in two years.

\section{Discussion}

This study which was conducted at KMCTH in year 2005 had total 15 cases of primary post-partum haemorrhage. The incidence was $2.1 \%$. 9 cases were of atonic primary post-partum haemorrhage solely. 2 cases were genital tract injuries, 1 case of retained placenta, 1 case of vulval haematoma and 2 cases were of combined cervical tear and atonic primary post-partum haemorrhage. Atonic post-partum haemorrhage remains most important cause as evidenced by most literature in the year 2005. In the year 2006 total number of deliveries was 835 and there were total 11 cases of post-partum haemorrhage. The incidence was $1.32 \%$. The trend changed from atonic PPH to traumatic PPH. Similar difference in incidence of atonic $(37.1 \%)$ and traumatic $\mathrm{PPH}(54.3 \%)$ was found in their study of $\mathrm{PPH}$ by Pradhan et $\mathrm{al}^{5}$. There were 8 cases of traumatic $\mathrm{PPH}$ and there were 2 cases of placenta accreta. There was one case of atonic PPH. This could be attributed to the active management of third stage of labour with which hospital has been practicing since July 2005 strictly. Overall incidence was $1.6 \%$ in two years.

If standard conservative management fails to control major post-partum haemorrhage and resulting consumption coagulapathy, the choice of surgery depends greatly on the surgeon's experience. The various method adopted are abdominal ligature of the uterine arteries as first described in $1952^{4}$. This method was used with various frequencies in 1960 and came out of fashion with advent of more potent uterotonic drugs. ${ }^{4}$ In 30 years review the success rate was $95 \%$ in 265 cases. $^{4}$

Internal iliac ligation is a similar simple method for controlling post-partum haemorrhage only $42 \%$ ligation were successful with immediate risk of injury to common iliac vein. ${ }^{4}$ Other side effects include central pelvic ischemia and resulting breakdown of perineal skin and post-partum ischemic lower motor neurone damages as well as ureteric lesion. Percutaneous uterine artery embolisation is applicable where the patient are cardio-vascular stable and to the rare situation where standby interventional radiology expertise is available. ${ }^{4}$ Packing the uterus with gauge in prostaglandins has been proposed but on the basis of only handful cases, the risks are ongoing bleeding and ascending infection. $^{4}$
Of 10 cases of atonic post-partum haemorrhage 6 were following Caesarean section. The primary treatment at KMCTH was to start with Oxytocic like high dose syntocinon infusion then, Eorgometrine injection and even Carboprost injections. The most frequent surgical procedure done was bilateral uterine artery ligation but it did not control bleeding as a single procedure. In one case it was complimented with bilateral ovarian artery ligation which together controlled the bleeding. In rest 5 cases B-Lynch brace suture was applied which finally controlled the bleeding. B-Lynch brace suture was applied in total 5 cases and successfully controlled the bleeding without further intervention. The better outcome was due to prompt recognition of the problem and early application of the treatment.

There were 2 maternal deaths following vaginal delivery. The poor outcome was due to delayed recognisation of the problem and poor condition of the patient at diagnosis. The first maternal death was of 26 years primi that underwent vaginal delivery. Per vaginal bleeding was noted after 4 hours. She was taken for EUA when treatment with ecbolics failed. Before going for laparotomy bleeding was tried to be controlled with balloon tamponade. At laparotomy she underwent Bilateral Uterine Artery Ligation and Brace Suture Application and 4 pint of blood. But unfortunately we lost the patient after half an hour of shifting to the ICU and second maternal death was of 23 years primi that underwent vaginal delivery. Per vaginal bleeding was noted after 6 hours of delivery. She had cervical tear and atonic PPH. She underwent hysterectomy but patient could not be revived back from shock.

Hysterectomy was done in three cases but not for atonic $\mathrm{PPH}$. One for was placenta accreta and two were for cervical tear. Emergency hysterectomy was perform mainly for scar rupture or uterine rupture $(41.1 \%)$ in as study by Pokharel et al. ${ }^{7}$ We were fortunate enough to successfully manage a case of amniotic fluid embolism which occurred before caesarean section. Patient was managed with ecbolics transfusion of blood products and good ventilatory support.

The imperfections of this study are:

1. The characterization of severity of each postpartum haemorrhage in terms of total blood loss is useful although approximate.

2. In this preliminary study quantification of the efficacy of any surgical procedure was not done for example of comparing pre-versus postprocedure blood loss, in $\mathrm{ml} / \mathrm{min}$ but took efficacy to be self evident by a virtually immediate and substantial reduction in blood loss, confirmed by subsequent stable haemodynamics. 
3. Ideally the introduction of B-Lynch brace suture new procedure should be justified in terms of the gold standard of randomised study design. Such a design is applicable to an elective procedure but unsuited to the clinical setting of massive refractory post partum haemorrhage, a fortunate rare and largely unpredictable emergency. Given the visually persuasive evidence of cause effect relationship between brace suture application and cessation of bleed loss there is no wish to seek ethical permission for a randomized study but rather to maintain safety of the procedure which till date has no adverse effect.

B-Lynch brace suture application should only be applied if bimanual compression decreased the amount of bleeding by abdominal and perineal inspection. In cases reported by B-lynch et.al two of five women had subsequent normal deliveries. The extreme degree of uterine compression with this technique raises concern about uterine antomic damage. The few women follow up had no uterine defects which might be secondary to rapid involution lessening the suture tension on each post partum day. The technique is easy to learn and can be also quickly performed and in my opinion the procedure should be belong the standard armamentarium of the practising obstetrician, especially in primigravidas whose obstetric career other wise prematurely and involuntarily end.

\section{Acknowledgement}

I am thankful to faculty members and staff of the Department of Obstetrics \& Gynaecology KMCTH for their active cooperation for preparing this article.

\section{Reference}

1. B - Lynch C., Coker A., Lawal AH, Abu J. and Cowen M.J. The B - Lynch surgical technique for the control of post-partum haemorrhage an alternative to hysterectomy? Five cases reported. Br J obset gynaecol 1997;104:372-375.

2. Ferguson J.E., Bourgeols F.J., underwood P.B., B- Lynch suture for post partum haemorrhage, Obstet gynaecol 2000;95:1020-1022.

3. Bhal K, Bhal N., Mulik V., Shankar L., The uterine compression sutures a valuable approach to control major haemorrhage at lower segment caesarean section. J obstet gynaecol Jan 2005;25(1):10-14.

4. Hebisch, MD and Huch Albert, MD, FRCOG, Vaginal Uterine Artery Ligation Avoids High Blood Loss and Puerperal Hysterectomy in Postpartum Hemorrhage, Obs \& gynae 2002:100;574-578.

5. Pradhan $\mathrm{P}$, Thapa magar S, Lama S Post partum hemorrhage in Teaching Hospital. NJOG 2006 May; 1(1): 26-29.

6. PredivolleWJ, ElbourneD, Mcdonalds et al. Active management of $3^{\text {rd }}$ stage of labour versus expectant.

7. Pokhrael H, Mukhapadhaya A, VaidhayaA, LamaDJ , Banerjee B , Pokhrael PK, Emergency Obstetric hysterectomy ; Experience at BP koirala Institute Sciences, NJOG 2006 May; 1(1): 34-37. 